\title{
ADVANCED DENTAL IMPLANT PLACEMENT TECHNIQUES
}

\author{
Ileri Düzeyde Implant Yerleştirme Teknikleri
}

Alex M. GREENBERG

Received: $25 / 08 / 2017$

Accepted:28/09/2017

ABSTRACT

The availability of in office Cone Beam CT (CBCT) scanners, dental implant planning software, CAD CAM milling, and rapid printing technologies allow for the precise placement of dental implants and immediate prosthetic temporization. These technologies allow for flapless implant placement, or open flap bone reduction for "All on 4" techniques with improved preoperative planning and intraoperative performance. CBCT permits practitioners in an office setting with powerful diagnostic capabilities for the evaluation of bone quality and quantity, as well as dental and osseous pathology essential for better informed dental implant treatment. CBCT provides the convenience of in office imaging and decreased radiation exposure. Rapid printing technologies provide decreased time and high accuracy for bone model and surgical guide fabrication.

Keywords: Cone Beam CT; surgical Guide; drill; planning; dental implant
$\ddot{O} Z$

Cone Beam CT (CBCT) taraylcllar, dental implant planlama yazılımı, CAD/CAM frezeleme ve hizl yazılım teknolojisi diş implantlarının yerleştirilme ve immediat protez yerleştirmeye müsaade etmektedir. Bu teknolojiler flepsiz implant yerleştirme veya preoperatif planlama ve introoperatif performans ile beraber "All on 4" teknikleri için açık cerrahi uygulamaya izin verir. CBTC, hekimlere kemik kalitesi ve miktarının yanı sıra diş ve kemik patolojisinin değerlendirilmesi için güçlü tanisal özelliklere sahip bir ofis ortamına da izin verir. CBTC, ofiste görüntülemede kolaylık sağlar ve radyasyona maruz kalma oranını düşürür. Hızlı baskı teknolojileri, cerrahi frez rehberi imalatı ve kemik modeli imalat, için azalan zaman ve yüksek doğruluk să̆lar.

Oral and Maxillofacial Surgery, Columbia University College of Dental Medicine, Attending, The New York Presbyterian Hospital,

The Mount Sinai Hospital, Mount Sinai Beth Israel Medical Center, and Mount Sinai West Hospital, New York, NY, USA 


\section{Introduction}

The virtual planning for the precise placement of dental implants using CT scanning, rapid printing and prototyping, optical scanning, and CAD CAM milling can now be utilized in a unified manner $(1,2)$. As a result of this progress from the digital technology, surgeons have improved diagnosis, with more accurate implant placement, and superior long term results. CT guided dental implant surgery allows decreased operating
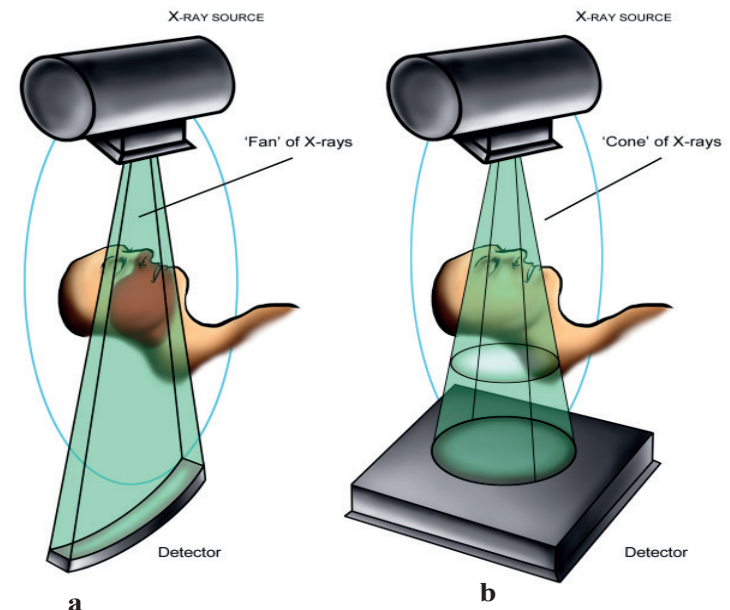

time, flapless procedures $(3,4)$, and decreased postoperative pain and swelling, and immediate temporization (5). The development of CT scanning from fan beam to spiral methods (6) has resulted in the development of in office Cone Beam CT (CBCT) scanners with decreased radiation dosage $(7,8)$ (Figure 1A, Figure 1B and Figure 1C) which are now widely available as standup, lie down, sitting and mobile CBCT units.

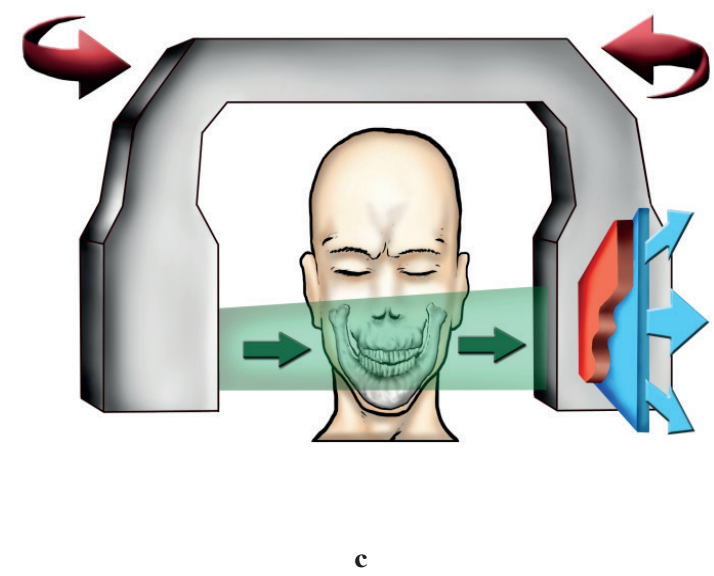

Figure 1. a. Fan Beam CT Scanner patient orientation, b. Cone Beam CT scanner patient orientation, and $\boldsymbol{c}$. Cone Beam CT Flat Plane Scanner for sitting or standup.

Plain tomography which was developed in the 1930's by Vallabona (9), and allowed the sectioning of an anatomic structure from the surrounding organs as a plain radiographic series of images, is the basis for CBCT. The orthopantamograph provides panoramic images and is an example of the continued use of plain tomography (10). The advent of computers, allowed the further development of plain tomography into a more sophisticated 3D imaging method. The concept for CT scanning was independently developed by Hounsfield and Cormack $(11,12)$, for which they were awarded the Nobel Prize in 1979 (13).

Hounsfield who created the first CT scanner that imaged the brain and later the whole body using the fan beam technique at EMI was funded by records sales from "The Beatles" $(14,15)$. With advances in computer and scintillator technology, spiral (helical) CT scanning machines were built. Based on the work of Kalender $(16,17)$. it was from the helical scanners that CBCT is derived. Radon's Transform developed in 1917 (18) (Figure 2), is the basic mathematical method for CT scanning and is based on back projection geometry (19, 20) (Figure 3).

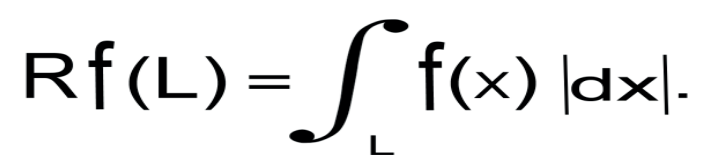

Figure 2. Radon's Transform mathematical formula. 


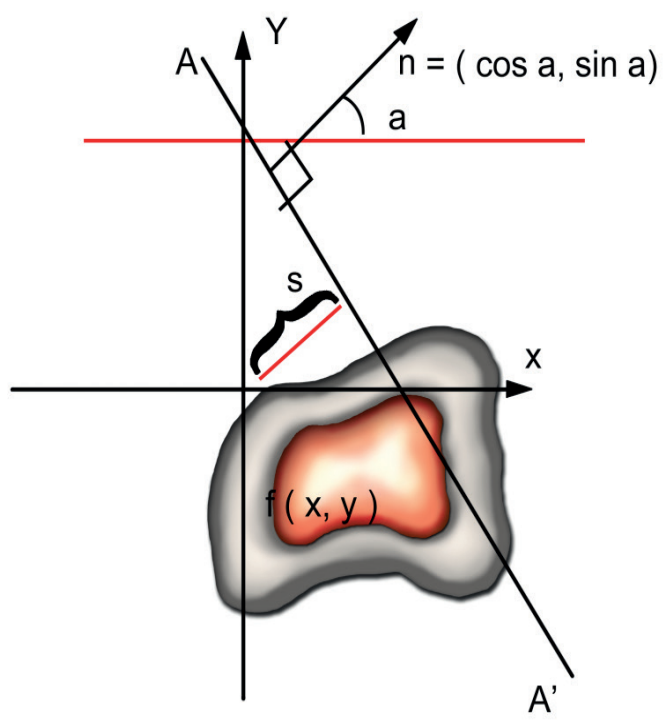

Figure 3. Radon's Transform back projection geometric diagram.

Methods for calculating the algorithm utilize either the Iterative Reconstruction (IR) (21), or Filtered Back Projection (FBP) (22). CBCT includes axial, sagittal, and coronal projections, 2D panoramic and lateral cephalometric images as well as $3 \mathrm{D}$ and oblique sagittal reformatted images (23).

With 72 million studies reported in the US, CT contributes to the increased radiation exposure to patients (24). Patients can be scanned at a significant reduction in radiation exposure using CBCT with powerful algorithms and lowered cancer risk compared to Helical CT $(25,26)$. In developed countries increased exposure of populations to radiation from $\mathrm{CT}$ scans has lead to considerable concern for increased cancer rates $(27,28)$.

Clinicians understanding of the radiation exposure of patients from plain and CT radiography is important to help decide when such studies are appropriate and to be able to answer patient concerns. Therefore, it is of importance to understand the radiation dosage from plain dental radiography and $\mathrm{CBCT}$.

The radiation exposure from plain dental radiography has been reviewed by Ludlow et al. (29) with the effective doses as: Full Mouth Exposures $=34.9-170.7,(\mu \mathrm{Sv})$, Bitewing $=5(\mu \mathrm{Sv})$, and Panoramic $=14.2-24.3(\mu \mathrm{Sv})$ and can be compared to the background annual radiation exposure from the environment $=3,100(\mu \mathrm{Sv})$ (30) . CBCT radiation dosage has been reported by Roberts et al. (31) and is found to be: Full FOV (Field of View) $206.2(\mu \mathrm{Sv}), 13 \mathrm{~cm}$ FOV $133.9(\mu \mathrm{Sv}), 6 \mathrm{~cm}$ FOV high resolution maxilla 93.3( $\mu \mathrm{Sv}), 5 \mathrm{~cm}$ FOV high resolution mandible $188.5(\mu \mathrm{Sv}), 6 \mathrm{~cm}$ standard mandible $96.2(\mu \mathrm{Sv})$, and $6 \mathrm{~cm}$ standard maxilla $58.9(\mu \mathrm{Sv})$. Different $\mathrm{CBCT}$ machines FOV radiation can vary from 51.7 to $193.4(\mu \mathrm{Sv})$.

The average radiation dosage from CBCT is substantially lower at $5-10 \%(51.7$ to $193.4(\mu \mathrm{Sv})$ when compared to a medical helical CT scan of the head $=2000(\mu \mathrm{Sv})(32)$. Concern regarding the lack of uniformity of various CBCT scanners actual radiation doses has been reported (33). Depending on the CBCT scanner and the FOV the radiation dosage equivalent to a multiple of panoramic radiographs which ranges from 2-4 $(15-78 \mu \mathrm{Sv})$ for a 12 " FOV scan and1-1 1/2 (5$33 \mu \mathrm{Sv}$ ) for a 9" FOV scan. By comparison the greatly increased risk of cancer from radiation exposure from a full body scan has been compared to the rate of cancer in atomic bomb survivors (34).

CBCT has become essential to contemporary dental implant treatment which allows the correct diagnosis through highly detailed representations of critical anatomic structures, precise measurements, and treatment planning in both $2 \mathrm{D}$ and $3 \mathrm{D}$.

CBCT images have excellent bone window resolution, but are lacking the soft tissue details of helical CT scans. Through the use of Hounsfield Units (35), range from $0-1000$, in which bone $=400+$, water $=0$, and air $=1000$ (36). CBCT can also provide the determination as to whether the patient has suitable bone density or not. CBCT provides imaging information regarding key anatomic structures such as the nasopalatine foramen (37) (Figure 4A and Figure 4B), mental foramina (38) (Figure 5), mandibular canals (39) (Figure 6), and sinus cavity (40) (Figure 7) positions. 
Greenberg $A M$

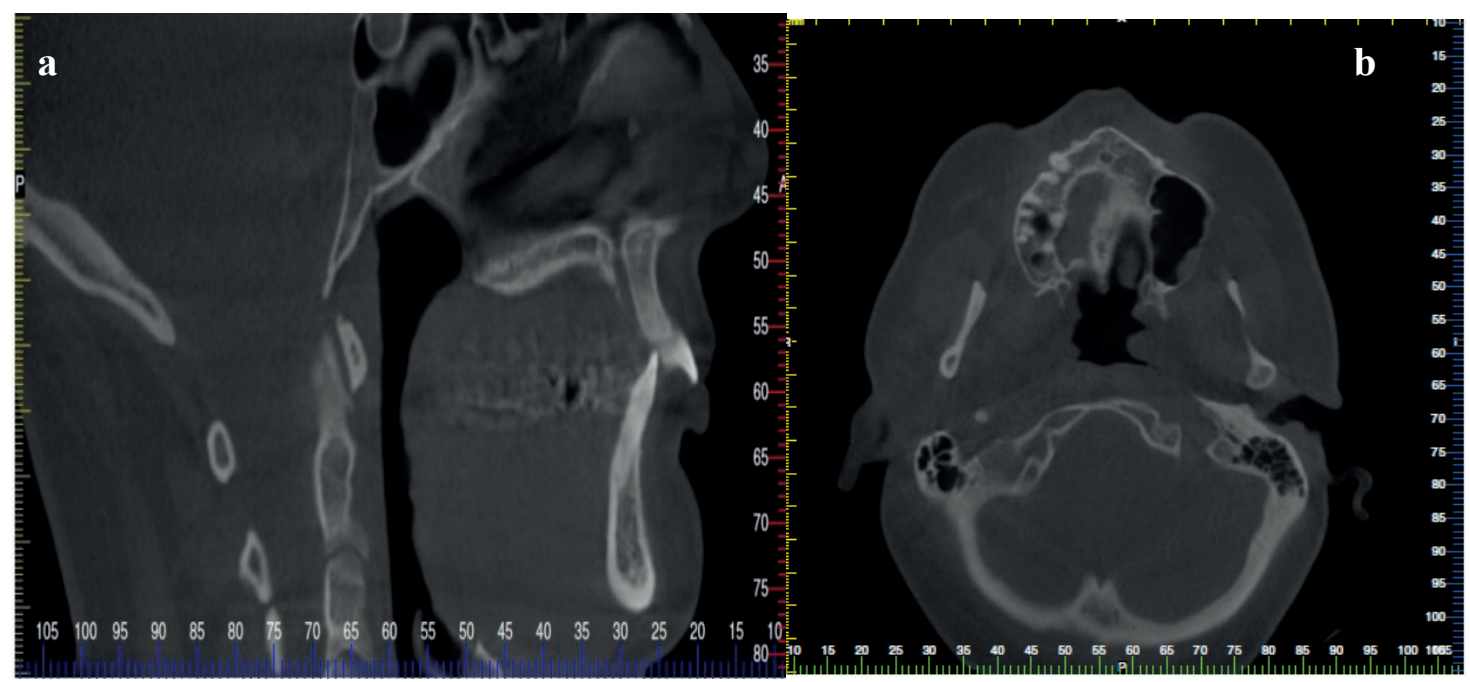

Figure 4. CBCT a. Incisive foramen axial view and $\boldsymbol{b}$. Incisive foramen sagittal view.

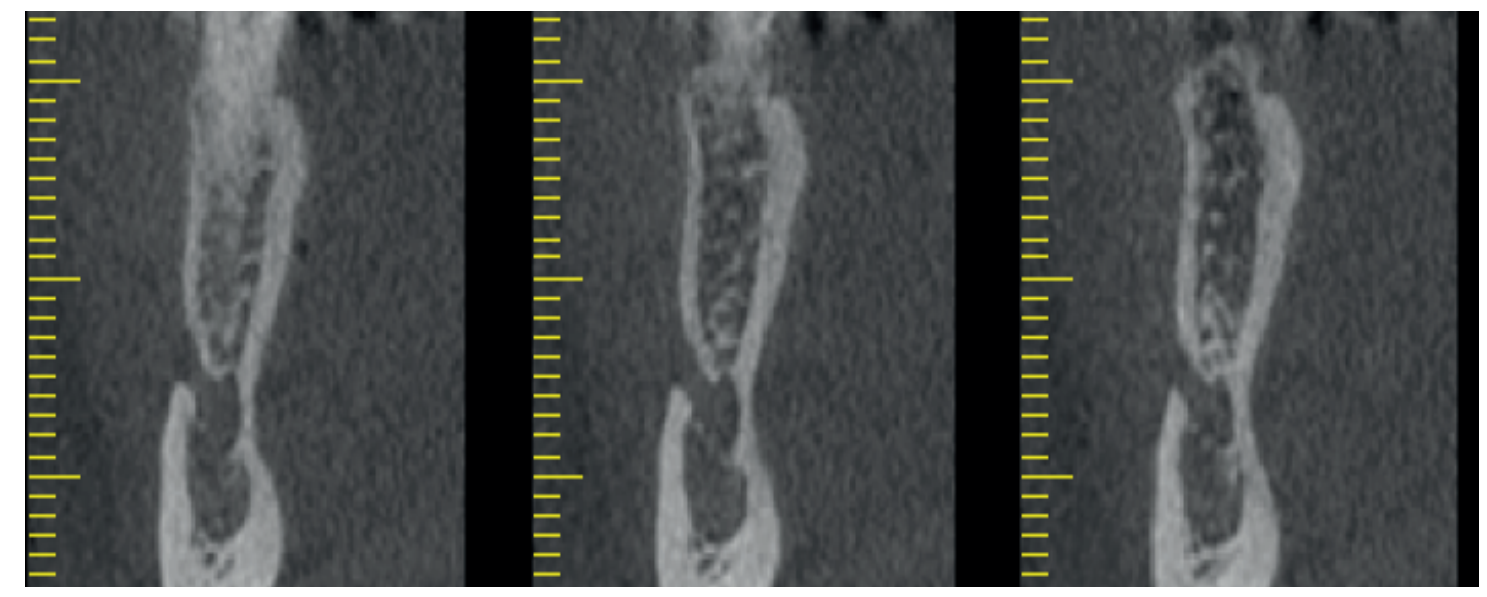

Figure 5. Mental foramen CBCT reformatted oblique sagittal view.

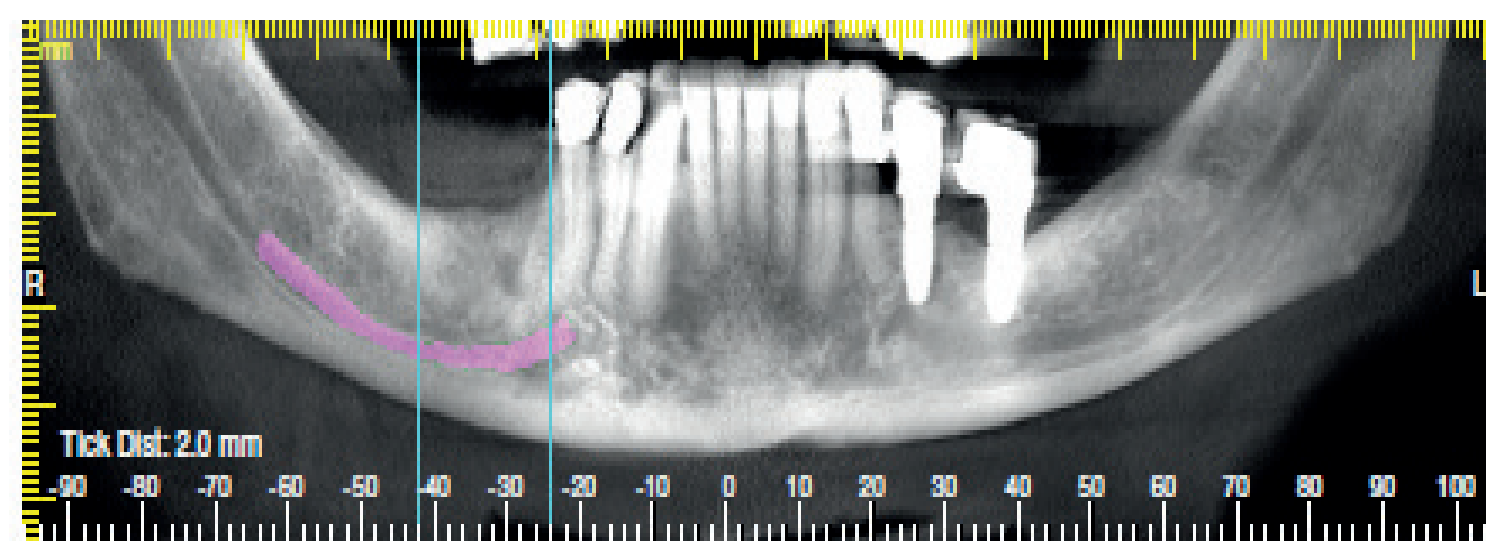

Figure 6a. Panoramic CBCT view of right mandibular missing second molar and marking of the left mandibular canal. 


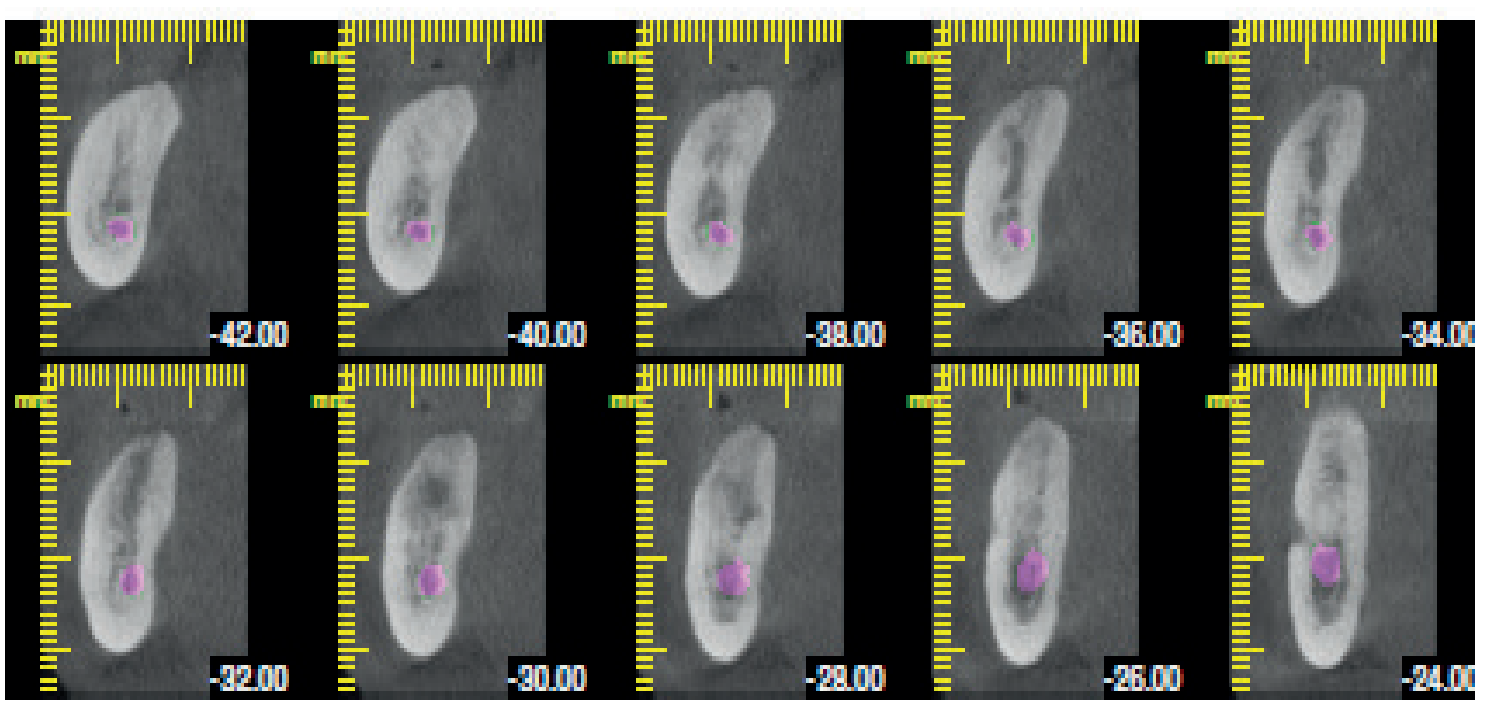

Figure 6b. Reformatted oblique sagittal CBCT views of right mandibular missing second molar and marking of the left mandibular canal.

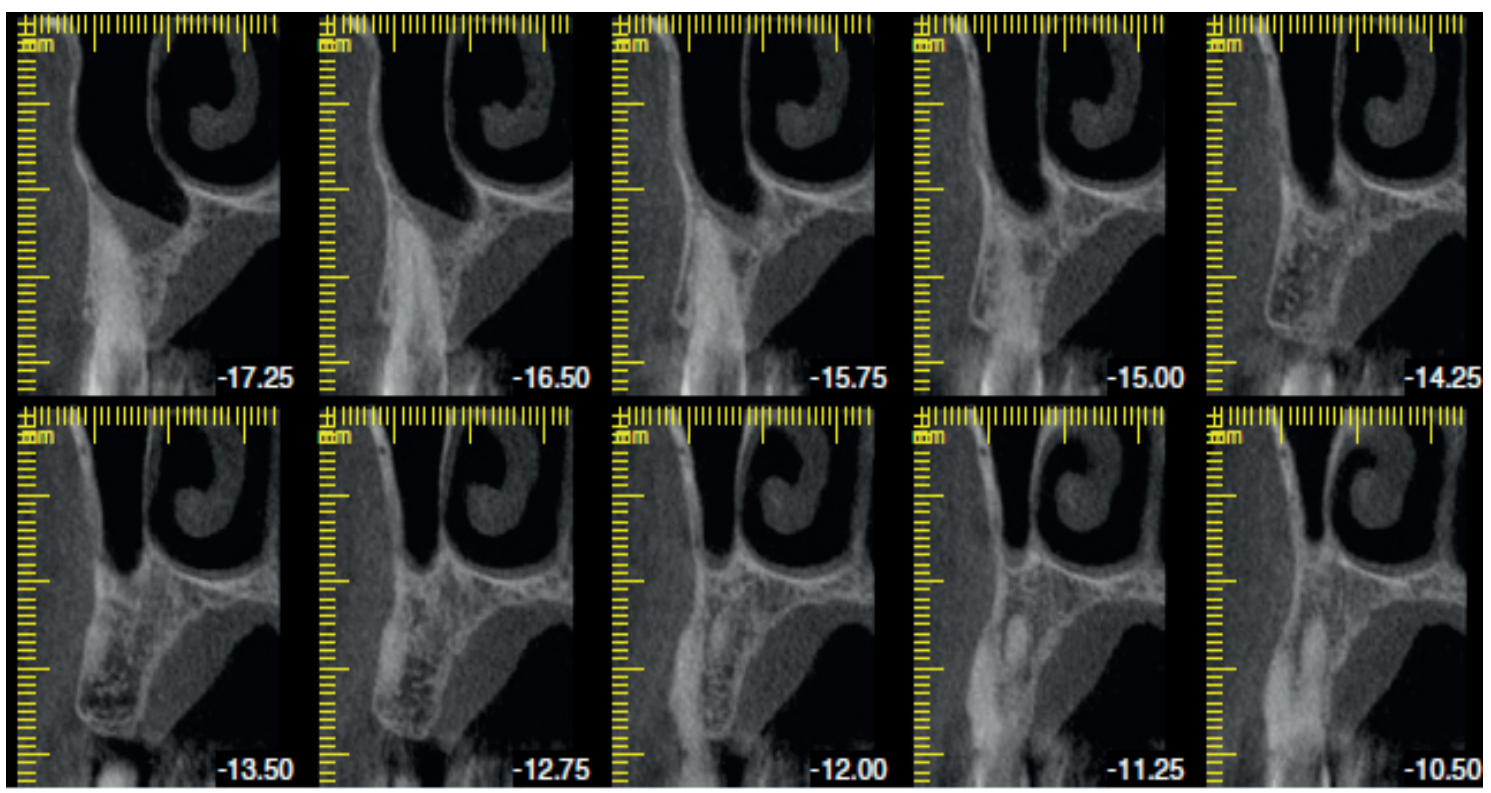

Figure 7. Reformatted oblique sagittal CBCT view of the maxillary sinus.

Visualization of these anatomic structures can help to prevent complications such as nerve injuries and injudicious sinus perforation. CBCT can also diagnose the presence of other dental or osseous pathology, whether cysts (41), impacted teeth (42), endodontic infections (43), periodontal disease (44), dental caries $(44,45)$, malignant (46) or benign tumors (47-49). For planning the placement of dental implants panoramic and reformatted oblique sagittal views are the most important (Figure 6A and 6B) $(23,50,51)$.

A rapid survey of the patient's panoramic view allows a general understanding of the dental condition, bone height, and the presence of pathology. Panoramic views require CBCT machines with Full Field of View (FOV), while machines with more limited views do not. Detailed cross sectional evaluation of the maxilla or mandible is provided by the reformatted oblique sagittal views provide information 
concerning the width and height of the bone $(23,50,51)$. Oblique sagittal views also allow better evaluation of the posterior mandible with the ability to mark the mandibular nerve, mental foramen, and incisive nerve branches (52-55) (Figure 6A and Figure 6B).

For dental implant planning the oblique sagittal images (Figures $6 \mathrm{~A}$ and $\mathrm{B}$ ) are the most important as they provide both the height and width dimensions as cross sectional images of the mandible or maxilla that are critical to planning dental implant trajectory and depth, and whether site development with localized bone graft augmentation is necessary. CBCT can also be utilized in extraction cases planning for simultaneous implant placement whether preoperative or following removal of the tooth (56) requires the use of the reformatted oblique sagittal views.

Planning in a virtual environment allows these images to be matched to a 3D image of the bone and dental prosthesis which permits a prosthetically driven dental implant placement (57) It is then not just a matter of placing the dental implant where there is sufficient bone, but also by taking into consideration the ideal position for the fabrication of the individual crown or multiple unit prosthesis. Prosthetically driven virtual planning dental implant positions to determine screw versus cement retained restorations which will have different trajectory positions for the prosthesis and dentition. CT guided depth control ensures the precise placement of dental implants for immediate restoration such as in full arch edentulous prosthesis such as "All on 4" types of cases (58), and the avoidance of injury to the mandibular nerves, mental foramen, and maxillary sinuses. Jenson et al. $(59,60)$ have reported on bone reduction using the "shelf technique" for the simultaneous placement of dental implants and prosthesis.

Modular templates with an outer framework containing a guide way can be utilized for bone reduction with a separate modular part containing master drill sleeves inserted for implant drill sequence and implant placement $(61,62)$. CBCT data can also be uploaded to other software applications and create a STL output for the fabrication of custom patient specific surgical drill guides by rapid printing or prototyping (Figure 8).

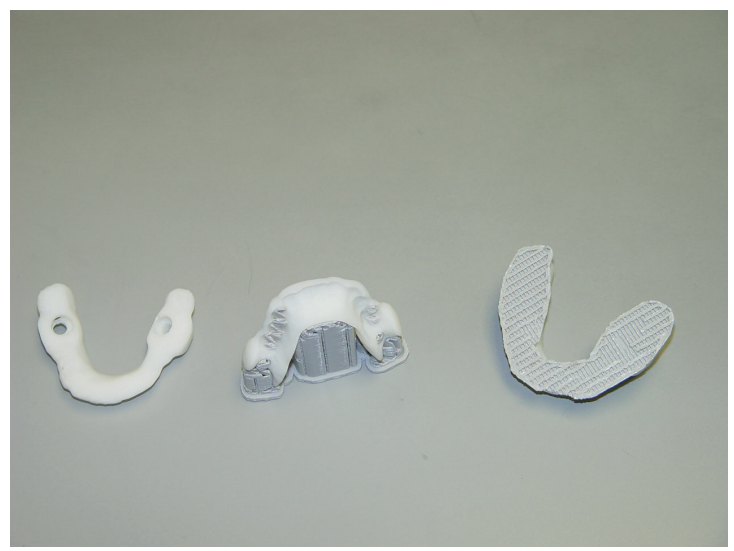

Figure 8. Rapid printed patient specific CT guided surgical drill template and example with scaffolding from $3 D$ printer still attached.

Through preoperative planning (63), the CT based patient specific surgical drill guide allows the surgeon to achieve the optimal implant positions. The use of presurgical software planning permits the determination of the need for site development with bone grafting, or if adequate bone height and width is present.

Whether simple or complex alveolar ridge augmentation, sinus bone augmentation via indirect and direct techniques, sites for immediate extraction and implant placement, teeth with decay, periodontal or endodontic infections can be preoperatively determined by CBCT and diagnosed. A variety of methods for the acquisition of the data which can include single scan, dual scan, combined CT and optical methods. Optical methods can include desktop scanning of a dental model, and the intraoral scanning of the patient's dentition (64).

The data sets can be merged so as to create a clean data set to manage the artifacts created from the scatter caused by gamma radiation particles striking metallic dental restorations (65) (Figure 9). 


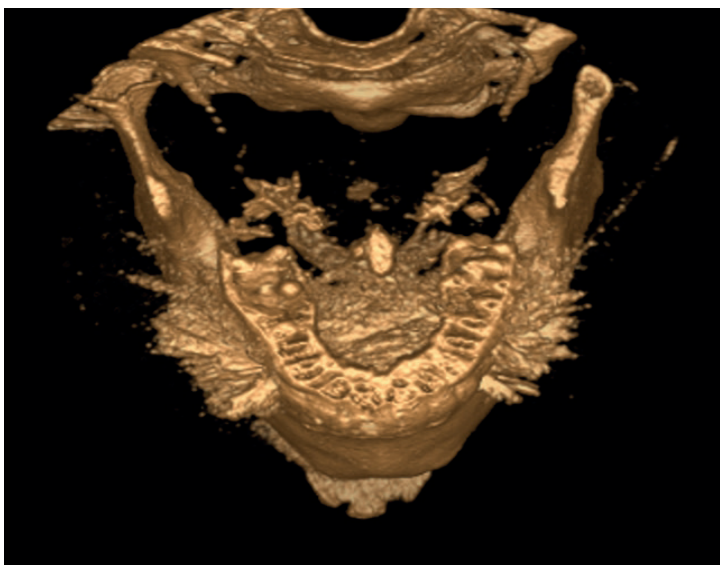

Figure 9. $3 D C B C T$ view of dental artifacts.

In order to perform the dual scan procedure, it is necessary to have a laboratory fabricated radiographic template which contains at least 6 gutta percha or metal bead fiducial markers (Figure 10). These fiducial markers permit the merger of two data sets (23).

One data set is of the patient with the radiographic template correctly seated in the mouth. The second data set is achieved by imaging of the radiographic template by itself in a styrofoam box (Figure 11).

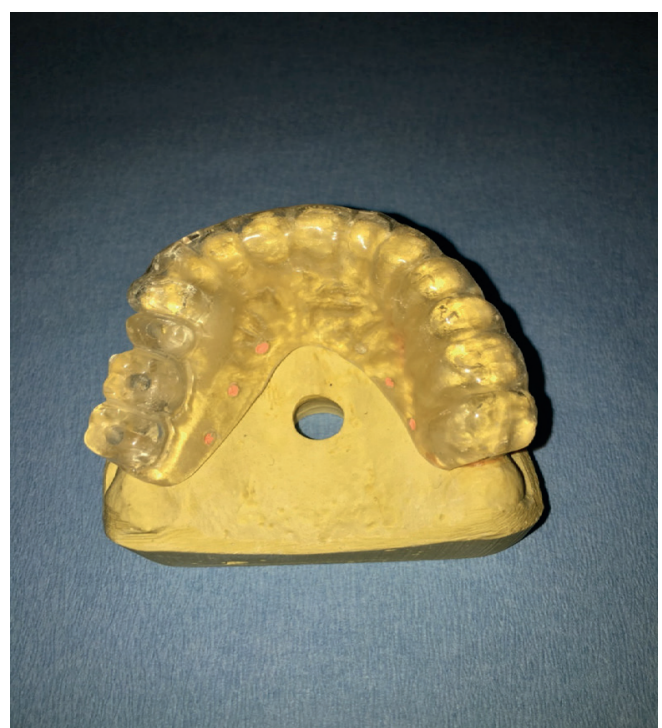

Figure 10. Laboratory fabricated radiographic template with 6 gutta percha markers.

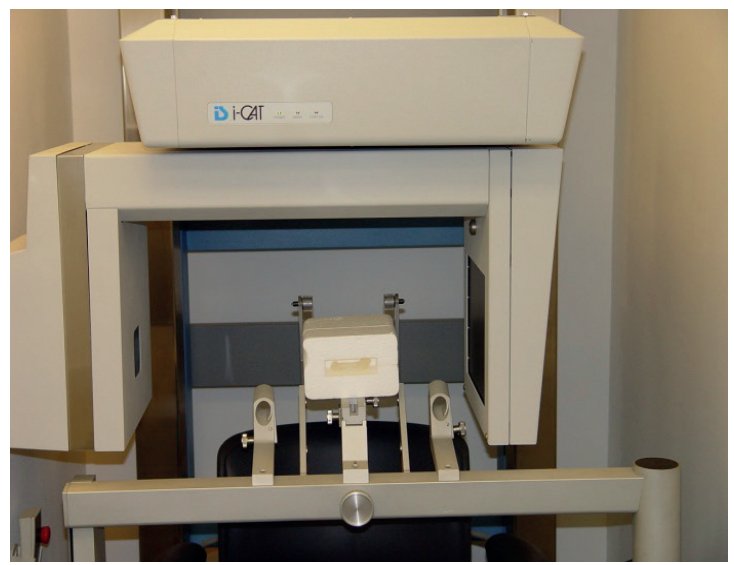

Figure 11. Radiographic template is contained within Styrofoam box for second scan in a CBCT Flat Plane Scanner. Styrofoam does not appear in the CBCT image because of its low density.

The purpose of using these two data sets is to produce an artifact free image of the radiographic template which has a clean image of the occlusal surfaces can then be manipulated by the planning software to contain the desired implant trajectories and a surgical drill guide is then rapid printed from the STL file.

Artifacts created from the gamma radiation striking the patient's dental metallic restorations create scatter effects in the $2 \mathrm{D}$ and $3 \mathrm{D}$ image that obscures the dental anatomy. The artifact obscured image prevents the production, of a well fitting surgicaldrill guide. The patients existing partial or complete all acrylic dentures can be used for the dual scanning process by placing the fiducial markers into the actual prosthesis which converts the removable partial or complete denture into a radiographic template.

The two data sets whether from the existing dentures or a laboratory fabricated radiographic template are then uploaded to a fileshare at a vendor's website so that the data sets can be merged, converted and then returned to the dentist for use in the planning software. The dual scan technique allows a clean image of the patient's dentition free of artifacts allows prosthetic planning and rapid printing of an accurately fitting drill guide for tooth borne cases, and is highly accurate because of the fiducial marker registration.

Software planning allows for the conversion of the virtual image of the patient's bony anatomy and planned dental implant positions and depths and by digital subtraction of the virtual template the fabrication of a surgical drill template produced by 
rapid manufacturing and rapid printing technologies (66) (Figure 12).

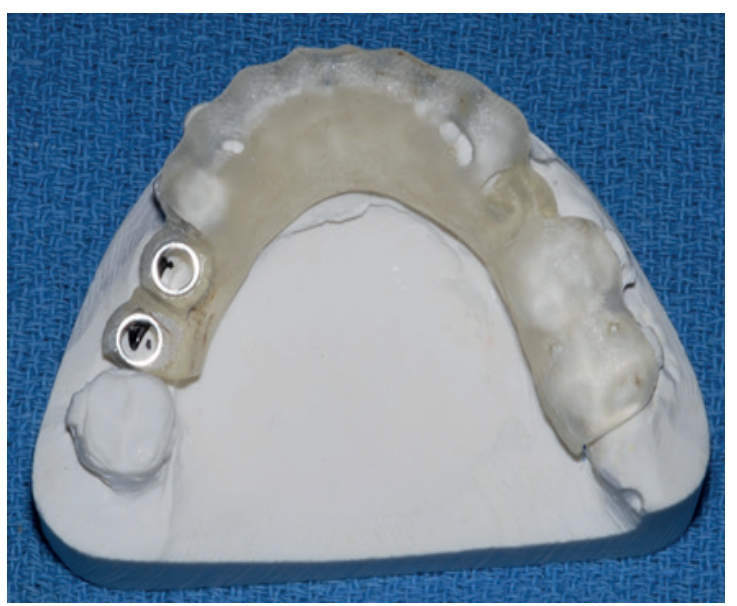

Figure 12. Rapid printed surgical template with metal master drill sleeves.

Once converted from the virtual image by rapid printing, the actual surgical drill guide will contain the precise information regarding the planned implant trajectories and surgical depth to be transferred to the patient. These guides can be bone borne, tooth borne, mucosal borne or in a combination of seatings (67).

Stabilization of surgical guides on the jaw can be performed by the surgeon's nondominant hand or assistant pressing the guide down, or fixation with surgical pins or screws. These screw or pin stabilizers channels can be planned in the software and produced as channels in the surgical drill guide (67).

The drill guides once fabricated have metal sleeves placed into the trajectories so that drill bits can be placed directly in them or through handles sized for different diameter drill bits fit into the master sleeves. Many dental implant manufacturers provide their own CT guided implant surgery drill kits.

These surgical kits provide all of the instrumentation necessary to perform CT guided implant surgery using rapid printed drill guides. When the procedure begins, if a flapless technique is being performed, after stabilizing the surgical drill guide, (Figure 13) the first step is to use the mucosal punch in a rotary instrument to remove a core of gingiva.

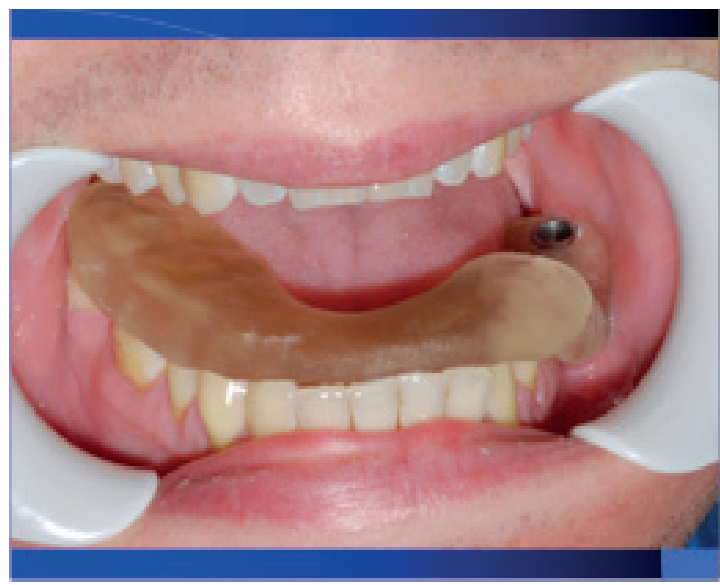

Figure 13. Rapid printed tooth borne surgical drill guide fitted demonstrating precise fit to occlusal surfaces.

\section{Case Report}

Clinical examples of case are presented so as to elaborate the technique of CT guided dental implant placement. A 22-year-old female presented with missing anterior mandibular teeth \#23-26 for dental implant placement. CBCT scan revealed an anterior mandibular superior alveolar buccal ridge inadequate width thickness. A radiographic guide was fabricated and dual scan imaging protocol performed and virtual planning for dental implants teeth \#23 and 26 with virtual conversion of the radiographic template into a surgical drill guide STL file which was rapid printed.

The metal drill sleeves were inserted and surgery was performed with removal of the bone graft fixation screws and placement of dental implants teeth \#23 and 26. After 4 months the implants were uncovered and fixed implant retained prosthesis was fabricated and placed. (Dental implant surgery: Dr. Alex M. Greenberg, NY, NY, Prosthodontics: Dr. Joel Hirsch, NY, NY). (Figures 14, 15, 16, 17, 18 and19). 


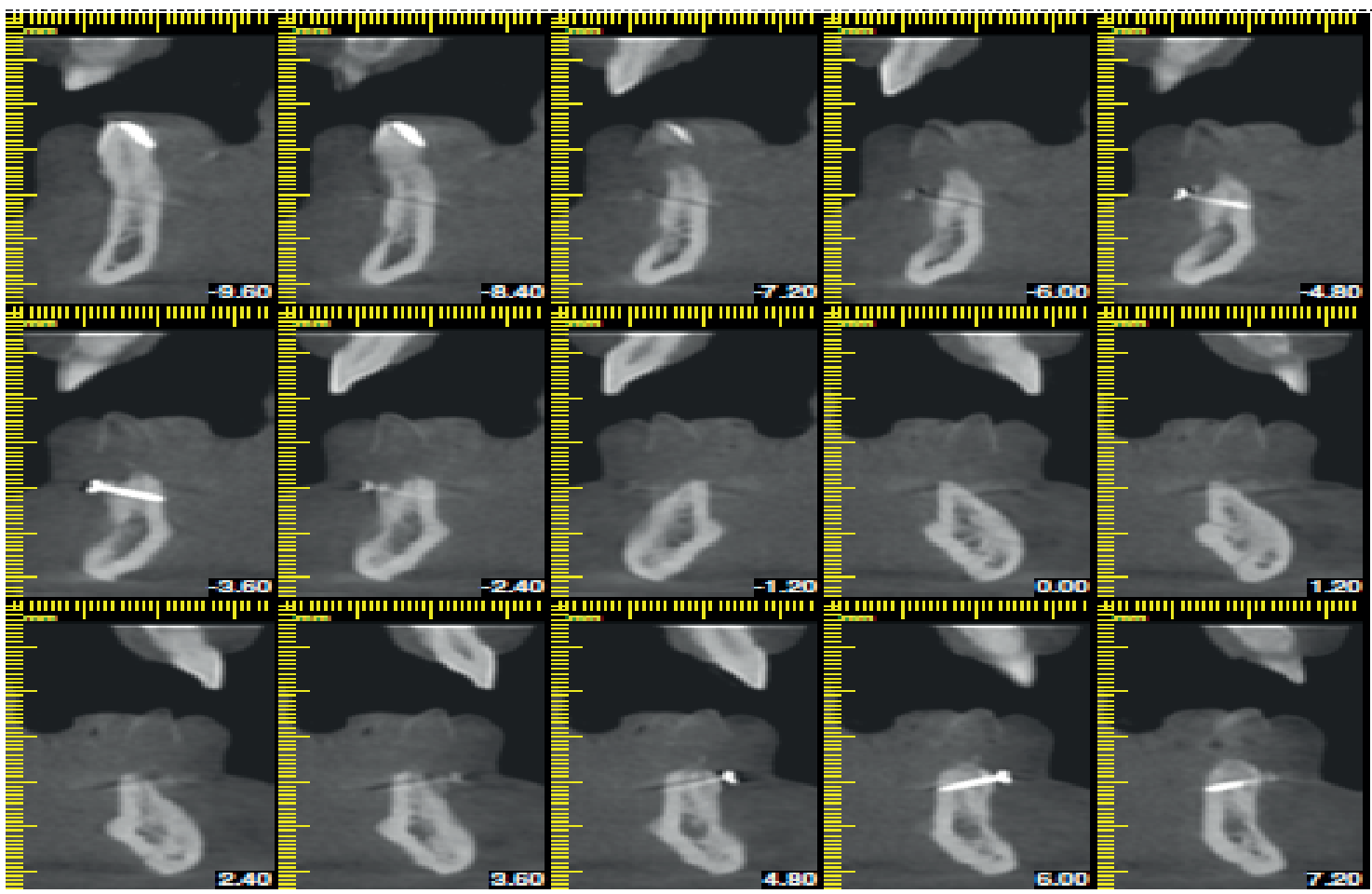

Figure 14. Anterior mandible missing teeth \#23-26 with inadequate superior alveolar ridge width thickness. Postoperative CBCT reformatted oblique sagittal view mandible missing teeth \#23-26 after bilateral chin block corticocancellous grafts repositioned to the buccal superior alveolar ridge with screw fixation region teeth \#23-26.

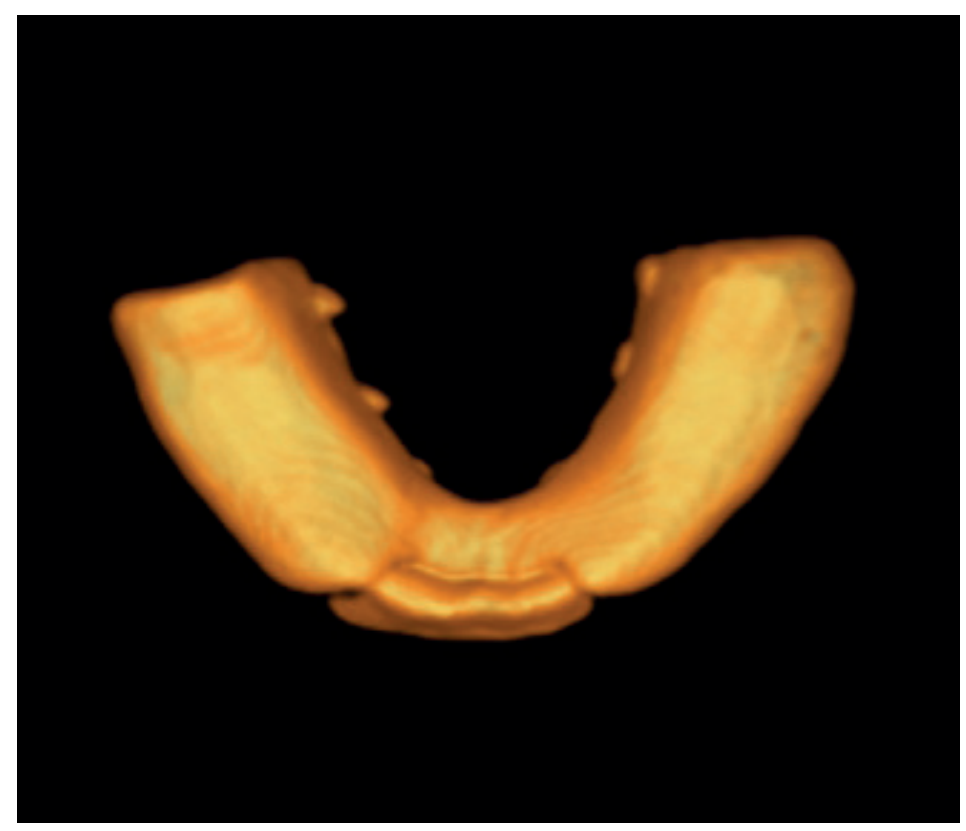

Figure 15. CBCT $3 D$ view of radiographic guide. 


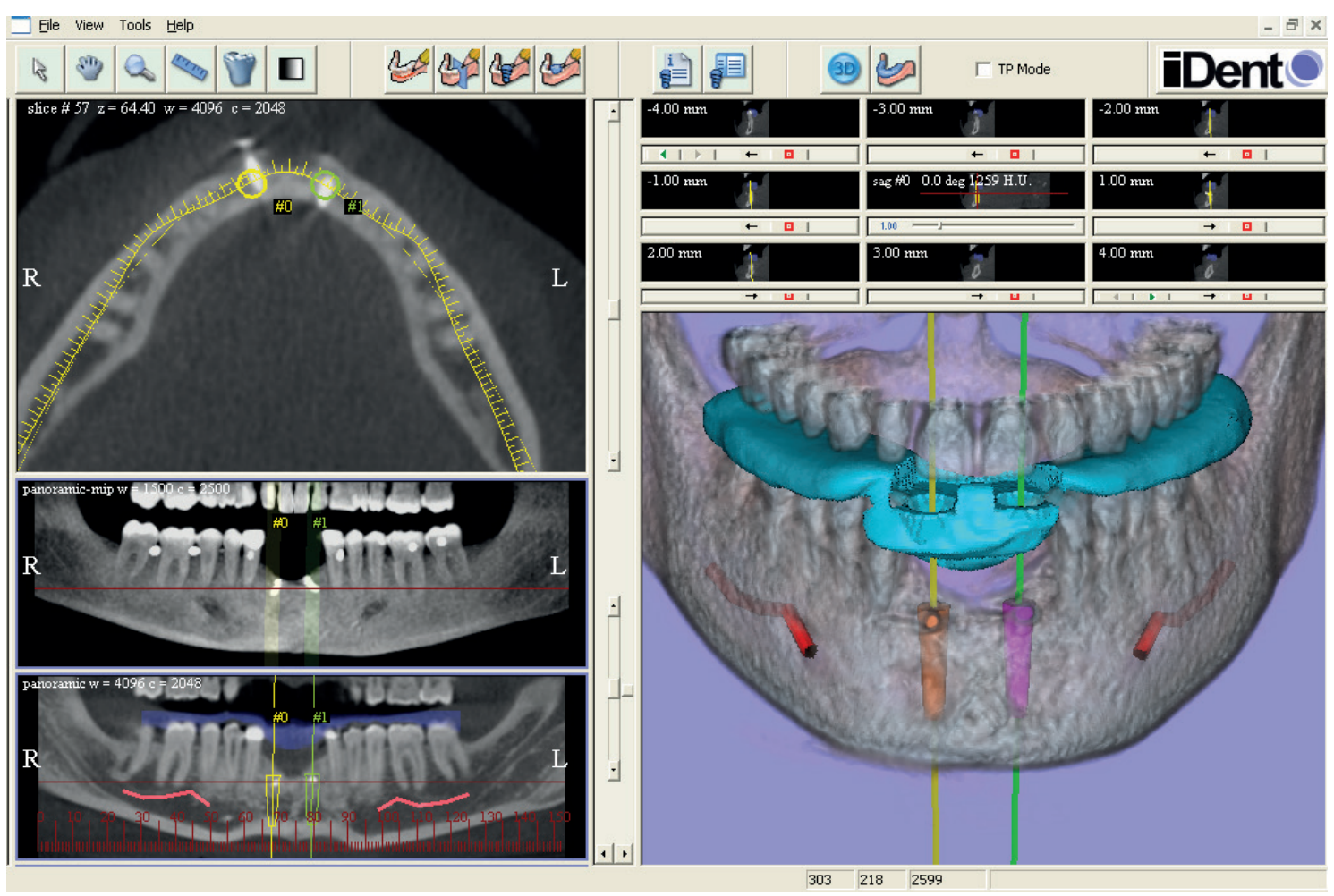

Figure 16. Virtual planning environment in all planes with $3 D$ view of radiographic template superimposed on transparent bone image with dental implant trajectories teeth \#23 and 26 (ImplantMaster iDent Imaging, Inc, New York, NY).
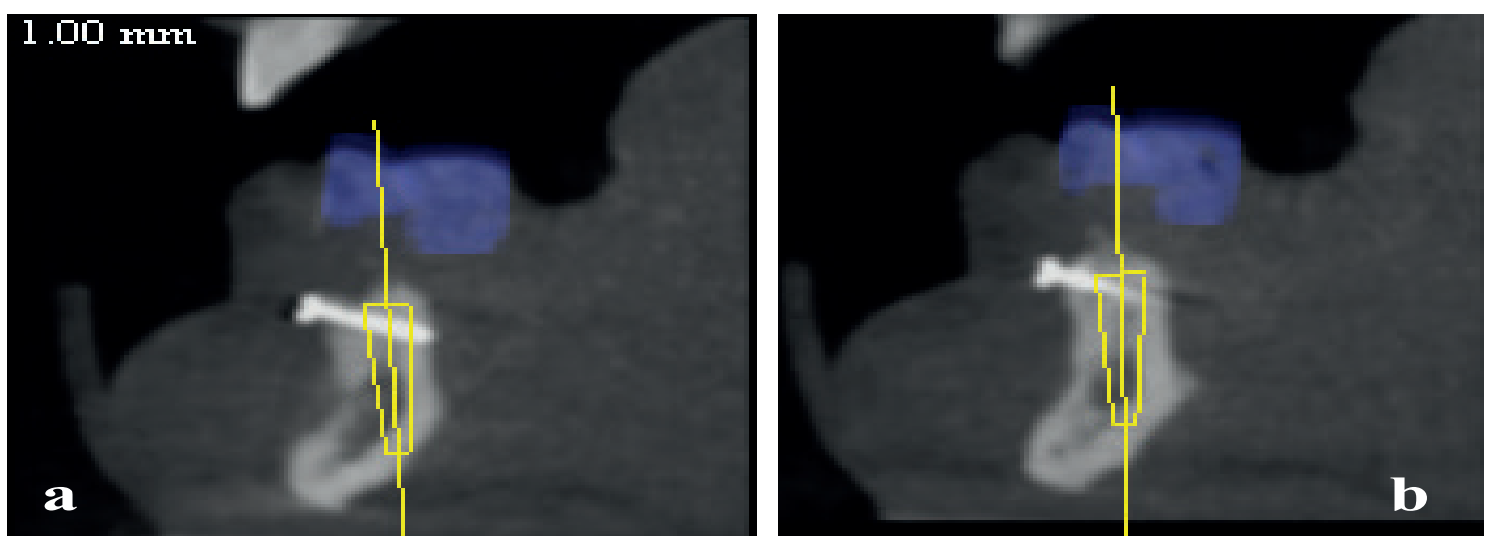

Figure 17. $\boldsymbol{a}$ and $\boldsymbol{b}$. Virtual planning environment oblique sagittal view of dental implant teeth \#23 (a) and 26 (b) (ImplantMaster iDent Imaging, Inc, New York, NY). 


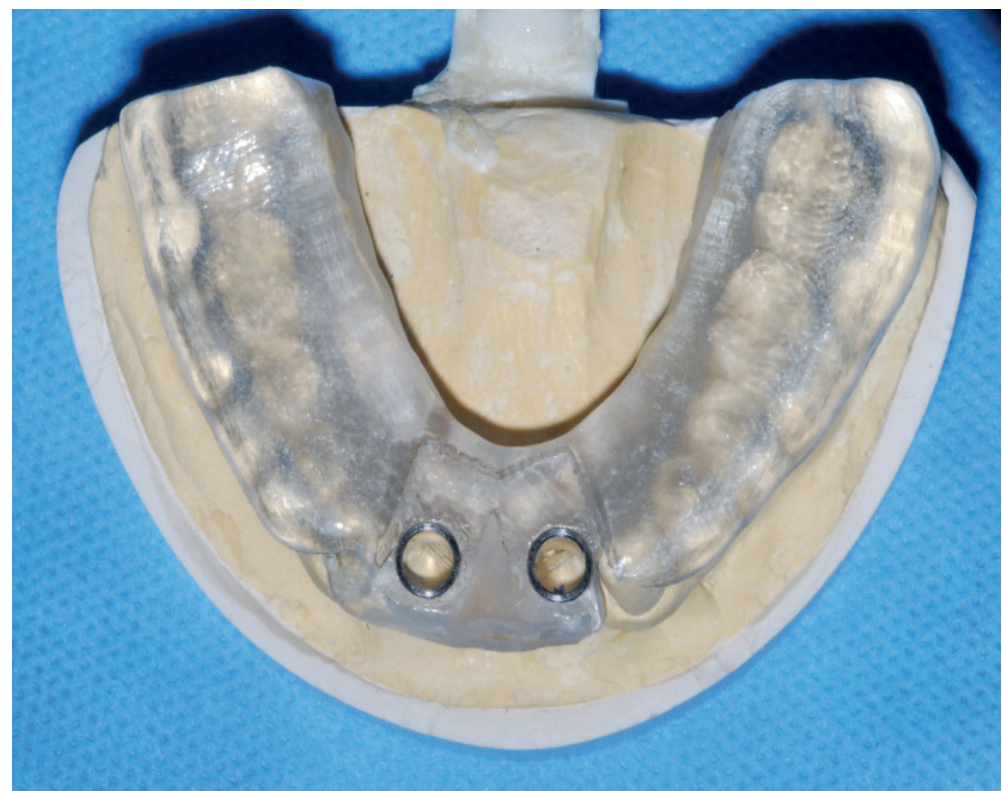

Figure 18. Rapid printed surgical drill guide. (iDent Imaging, Inc, New York, NY, Figure used with Permission, Greenberg AM Ed. Digital Technologies in Craniomaxillofacial Surgery, Springer Verlag New York, In Press).

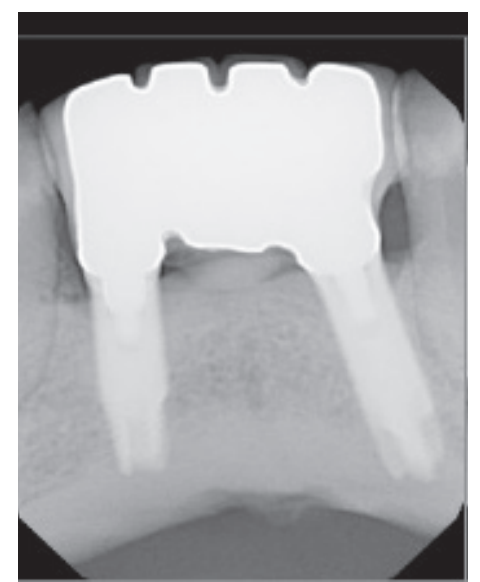

Figure 19. Postoperative completion film of implant retained fixed prosthesis teeth \#23 and 26.

\section{Conclusion}

CBCT has become an important in office or scanning center based dental imaging technology, providing powerful diagnostic capabilities and practical applications. Software planning for dental implant placement allows preoperative diagnosis, precise planning and trajectories, and the fabrication of rapid printed surgical drill guides. New technologies of CAD CAM milling, optical scanning, and modular implant fabrication will allow further advances in this rapidly developing aspect of dental implant treatment.

\section{Source of funding \\ None declared.}

\section{Conflict of interest}

Author disclosed receiving a grant from Straumann Group as a relevant financial activity outside the submitted work. Author disclosed holding the rights of intellectual properties (issued patent, number: US 9,050,665 and US 8,750, 590) for two items mentioned in this article.

\section{References}

1. Jacobs R, Adriansens A, Naert I, Quirynen M, Hermans R, Van Steenberghe D. Predictability of reformatted computed tomography for preoperative planning of endosseous implants. Dentomaxillofac Radiol 1999;28(1):37-41.

2. Tardieu PB, Vrielinck L, Escolano E, Henne M, Tardieu AL. Computer-assisted implant placement: Scan template, simplant, surgiguide, and safe system. Int $\mathrm{J}$ Periodontics Restorative Dent 2007;27(2):141-149.

3. Kamposiora P, Papavasiliou G, Madianos P. Presentation of two cases of immediate restoration 
Greenberg $A M$

of implants in the esthetic region, using facilitate software and guides with stereolithographic model surgery prior to patient surgery. J Prosthodont 2012;21(2):130-137.

4. van Steenberghe D, Glauser R, Blomback U, Andersson M, Schutyser F, Pettersson A, Wendelhag I. A computed tomographic scanderived customized surgical template and fixed prosthesis for flapless surgery and immediate loading of implants in fully edentulous maxillae: A prospective multicenter study. Clin Implant Dent Relat Res 2005;7 Suppl 1:S111-120.

5. Amorfini L, Storelli S, Romeo E. Rehabilitation of a dentate mandible requiring a full arch rehabilitation. Immediate loading of a fixed complete denture on 8 implants placed with a bone-supported surgical computer-planned guide: A case report. J Oral Implantol 2011;37 Spec No:106-113.

6. Rubin GD. Computed tomography: Revolutionizing the practice of medicine for 40 years. Radiology 2014;273(2 Suppl):S45-74.

7. Chau AC, Fung K. Comparison of radiation dose for implant imaging using conventional spiral tomography, computed tomography, and conebeam computed tomography. Oral Surg Oral Med Oral Pathol Oral Radiol Endod 2009;107(4):559565.

8. Rugani P, Kirnbauer B, Arnetzl GV, Jakse N. Cone beam computerized tomography: Basics for digital planning in oral surgery and implantology. Int J Comput Dent 2009;12(2):131-145.

9. Oliva L. [Alessandro vallebona (1899-1987)]. Radiol Med 1988;76(1-2):127-129.

10. Scarfe WC, Eraso FE, Farman AG. Characteristics of the orthopantomograph op 100. Dentomaxillofac Radiol 1998;27(1):51-57.

11. Beckmann EC. "Godfrey Newbold Hounsfield". Physics Today 2005;58(3):84-85.

12. Shampo MA, Kyle RA. Allan Cormack-codeveloper of computed tomographic scanner. Mayo Clin Proc 1996;71(3):288.

13. Raju TN. The Nobel chronicles. 1979: Allan Macleod Cormack (b 1924); and Sir Godfrey Newbold Hounsfield (b 1919). Lancet 1999;354(9190):1653.

14. Goodman LR. The beatles, the Nobel prize, and CT scanning of the chest. Radiol Clin North Am 2010;48(1):1-7.

15. Sittig DF, Ash JS, Ledley RS. The story behind the development of the first whole-body computerized tomography scanner as told by Robert S. Ledley. J Am Med Inform Assoc 2006;13(5):465-469.

16. Kalender WA, Vock P, Polacin A, Soucek M. [spiral-CT: A new technique for volumetric scans. I. Basic principles and methodology]. Rontgenpraxis 1990;43(9):323-330.

17. Soucek M, Vock P, Daepp M, Kalender WA. [spiral-ct: A new technique for volumetric scans. II. Potential clinical applications]. Rontgenpraxis 1990;43(10):365-375.

18. Hornich H. A tribute to Johann Radon IEEE Trans Med Imaging 1986;5(4):169.

19. Anastasio MA, Pan X, Clarkson E. Comments on the filtered backprojection algorithm, range conditions, and the pseudoinverse solution. IEEE Trans Med Imaging 2001;20(6):539-542.

20. Wininger KL. Basis of CT: The Radon transform. Radiol Technol 2013;84(4):413-418.

21. Zhang-O'Connor Y, Fessler JA. Fourier-based forward and back-projectors in iterative fan-beam tomographic image reconstruction. IEEE Trans Med Imaging 2006;25(5):582-589.

22. Pan X, Sidky EY, Vannier M. Why do commercial CT scanners still employ traditional, filtered backprojection for image reconstruction? Inverse Probl 2009;25(12):1230009.

23. Greenberg A. Basics of Cone-Beam CT and CT guided dental implant surgery. Selected Readings in Oral and Maxillofacial Surgery 2011;19(5):148.

24. Brenner DJ, Hall EJ. Computed tomography--an increasing source of radiation exposure. N Engl J Med 2007;357(22):2277-2284.

25. Lee CY, Koval TM, Suzuki JB. Low-dose radiation risks of computerized tomography and cone beam computerized tomography: Reducing the fear and controversy. J Oral Implantol 2015;41(5):e223-230.

26. Pauwels R, Cockmartin L, Ivanauskaite D, Urboniene A, Gavala S, Donta C, Tsiklakis K, Jacobs R, Bosmans H, Bogaerts R, Horner K, Consortium SP. Estimating cancer risk from dental cone-beam CT exposures based on skin dosimetry. Phys Med Biol 2014;59(14):38773891.

27. Berrington de Gonzalez A, Mahesh M, Kim KP, Bhargavan M, Lewis R, Mettler F, Land C. Projected cancer risks from computed tomographic scans performed in the United States in 2007. Arch Intern Med 2009;169(22):20712077. 
28. Shuryak I, Sachs RK, Brenner DJ. A new view of radiation-induced cancer. Radiat Prot Dosimetry 2011;143(2-4):358-364.

29. Ludlow JB, Davies-Ludlow LE, White SC. Patient risk related to common dental radiographic examinations: The impact of 2007 international commission on radiological protection recommendations regarding dose calculation. J Am Dent Assoc 2008;139(9):12371243.

30. National Council on Radiation Protection and Measurements. Ionizing radiation exposure of the population of the United States. Bethesda, MD: National Council on Radiation Protection and Measurements; NCRP Report No. 160; 2006.

31. Roberts JA, Drage NA, Davies J, Thomas DW. Effective dose from cone beam CT examinations in dentistry. Br J Radiol 2009;82(973):35-40.

32. Mettler FA, Jr., Huda W, Yoshizumi TT, Mahesh M. Effective doses in radiology and diagnostic nuclear medicine: A catalog. Radiology 2008;248(1):254-263.

33. Kamburoglu K. Use of dentomaxillofacial cone beam computed tomography in dentistry. World J Radiol 2015;7(6):128-130.

34. Brenner DJ, Elliston CD. Estimated radiation risks potentially associated with full-body CT screening. Radiology 2004;232(3):735-738.

35. Brooks RA. A quantitative theory of the hounsfield unit and its application to dual energy scanning. J Comput Assist Tomogr 1977;1(4):487-493.

36. Greenberg AM. Cone beam computed tomography scanning and diagnosis for dental implants. Oral Maxillofac Surg Clin North Am 2015;27(2):185-202.

37. Mardinger O, Namani-Sadan N, Chaushu G, Schwartz-Arad D. Morphologic changes of the nasopalatine canal related to dental implantation: A radiologic study in different degrees of absorbed maxillae. J Periodontol 2008;79(9):1659-1662.

38. Sheikhi M, Karbasi Kheir M, Hekmatian E. Cone-beam computed tomography evaluation of mental foramen variations: A preliminary study. Radiol Res Pract 2015;2015:124635.

39. Pertl L, Gashi-Cenkoglu B, Reichmann J, Jakse N, Pertl C. Preoperative assessment of the mandibular canal in implant surgery: Comparison of rotational panoramic radiography
(OPG), computed tomography (CT) and cone beam computed tomography (CBCT) for preoperative assessment in implant surgery. Eur J Oral Implantol 2013;6(1):73-80.

40. Neugebauer J, Ritter L, Mischkowski RA, Dreiseidler T, Scherer P, Ketterle M, Rothamel D, Zoller JE. Evaluation of maxillary sinus anatomy by cone-beam ct prior to sinus floor elevation. Int $\mathrm{J}$ Oral Maxillofac Implants 2010;25(2):258-265.

41. Weber AL. Imaging of cysts and odontogenic tumors of the jaw. Definition and classification. Radiol Clin North Am 1993;31(1):101-120.

42. Katheria BC, Kau CH, Tate R, Chen JW, English J, Bouquot J. Effectiveness of impacted and supernumerary tooth diagnosis from traditional radiography versus cone beam computed tomography. Pediatr Dent 2010;32(4):304-309.

43. Kruse C, Spin-Neto R, Wenzel A, Kirkevang LL. Cone beam computed tomography and periapical lesions: A systematic review analysing studies on diagnostic efficacy by a hierarchical model. Int Endod J 2015;48(9):815-828.

44. Tyndall DA, Rathore S. Cone-beam ct diagnostic applications: Caries, periodontal bone assessment, and endodontic applications. Dent Clin North Am 2008;52(4):825-841, vii.

45. Zhang ZL, Qu XM, Li G, Zhang ZY, Ma XC. The detection accuracies for proximal caries by cone-beam computerized tomography, film, and phosphor plates. Oral Surg Oral Med Oral Pathol Oral Radiol Endod 2011;111(1):103-108.

46. Hariya Y, Yuasa K, Nakayama E, Kawazu T, Okamura K, Kanda S. Value of computed tomography findings in differentiating between intraosseous malignant tumors and osteomyelitis of the mandible affecting the masticator space. Oral Surg Oral Med Oral Pathol Oral Radiol Endod 2003;95(4):503-509.

47. Araki M, Kameoka S, Matsumoto N, Komiyama $\mathrm{K}$. Usefulness of cone beam computed tomography for odontogenic myxoma. Dentomaxillofac Radiol 2007;36(7):423-427.

48. Cassatly MG, Greenberg AM, Kopp WK. Bilateral giant cell granulomata of the mandible: Report of case. J Am Dent Assoc 1988;117(6):731-733.

49. Cavalcanti MG, Ruprecht A, Vannier MW. Evaluation of an ossifying fibroma using three-dimensional computed tomography. Dentomaxillofac Radiol 2001;30(6):342-345. 
50. Braut V, Bornstein MM, Lauber R, Buser D. Bone dimensions in the posterior mandible: A retrospective radiographic study using cone beam computed tomography. Part 1--analysis of dentate sites. Int J Periodontics Restorative Dent 2012;32(2):175-184.

51. Greenberg AM. Digital technologies for dental implant treatment planning and guided surgery. Oral Maxillofac Surg Clin North Am 2015;27(2):319-340.

52. Jacobs R, Mraiwa N, vanSteenberghe D, Gijbels F, Quirynen M. Appearance, location, course, and morphology of the mandibular incisive canal: An assessment on spiral ct scan. Dentomaxillofac Radiol 2002;31(5):322-327.

53. Kuribayashi A, Watanabe H, Imaizumi A, Tantanapornkul W, Katakami K, Kurabayashi T. Bifid mandibular canals: Cone beam computed tomography evaluation. Dentomaxillofac Radiol 2010;39(4):235-239.

54. Naitoh M, Hiraiwa Y, Aimiya H, Gotoh K, Ariji E. Accessory mental foramen assessment using cone-beam computed tomography. Oral Surg Oral Med Oral Pathol Oral Radiol Endod 2009;107(2):289-294.

55. Uchida Y, Noguchi N, Goto M, Yamashita Y, Hanihara T, Takamori H, Sato I, Kawai T, Yosue T. Measurement of anterior loop length for the mandibular canal and diameter of the mandibular incisive canal to avoid nerve damage when installing endosseous implants in the interforaminal region: A second attempt introducing cone beam computed tomography. J Oral Maxillofac Surg 2009;67(4):744-750.

56. De Santis D, Canton LC, Cucchi A, Zanotti G, Pistoia E, Nocini PF. Computer-assisted surgery in the lower jaw: Double surgical guide for immediately loaded implants in postextractive sites-technical notes and a case report. J Oral Implantol 2010;36(1):61-68.

57. Rosenfeld AL, Mandelaris GA, Tardieu PB. Prosthetically directed implant placement using computer software to ensure precise placement and predictable prosthetic outcomes. Part 1: Diagnostics, imaging, and collaborative accountability. Int J Periodontics Restorative Dent 2006;26(3):215-221.

58. Malo P, de Araujo Nobre M, Lopes A, Ferro A, Gravito I. All-on-4(r) treatment concept for the rehabilitation of the completely edentulous mandible: A 7-year clinical and 5-year radiographic retrospective case series with risk assessment for implant failure and marginal bone level. Clin Implant Dent Relat Res 2015;17 Suppl 2:e531-541.

59. Jensen OT, Adams MW, Cottam JR, Parel SM, Phillips WR, 3rd. The all-on-4 shelf: Maxilla. J Oral Maxillofac Surg 2010;68(10):2520-2527.

60. Jensen OT, Adams MW, Cottam JR, Parel SM, Phillips WR, 3rd. The all on 4 shelf: Mandible. J Oral Maxillofac Surg 2011;69(1):175-181.

61. US 9,050,665

62. US 8,750,590

63. Valente F, Schiroli G, Sbrenna A. Accuracy of computer-aided oral implant surgery: A clinical and radiographic study. Int J Oral Maxillofac Implants 2009;24(2):234-242.

64. Flugge TV, Nelson K, Schmelzeisen R, Metzger MC. Three-dimensional plotting and printing of an implant drilling guide: Simplifying guided implant surgery. J Oral Maxillofac Surg 2013;71(8):1340-1346.

65. Cremonini CC, Dumas M, Pannuti CM, Neto JB, Cavalcanti MG, Lima LA. Assessment of linear measurements of bone for implant sites in the presence of metallic artefacts using cone beam computed tomography and multislice computed tomography. Int J Oral Maxillofac Surg 2011;40(8):845-850.

66. Van de Wiele G, Teughels W, Vercruyssen M, Coucke W, Temmerman A, Quirynen M. The accuracy of guided surgery via mucosa-supported stereolithographic surgical templates in the hands of surgeons with little experience. Clin Oral Implants Res 2015;26(12):1489-1494.

67. Greenberg AM and Schmelzeisen R Eds, Craniomaxillofacial Reconstructive and Corrective Bone Surgery New York: Springer Verlag, In press.

\section{Corresponding Author:}

Alex M. GREENBERG D.D.S.

Assistant Clinical Professor

Columbia University College of Dental

Medicine Division and Oral and

Maxillofacial Surgery

Practice Limited to Oral and Maxillofacial

Surgery

18 East 48th Street Suite 1702

New York, NY 10017 USA

email: nycimplant@aol.com 